\title{
LITERATURA COMPARADA E TRADUÇÃO: CONFLUÊNCIAS
}

\author{
Andréia Guerini* \\ Universidade Federal de Santa Catarina/CNPq
}

Walter Carlos Costa**

Universidade Federal de Santa Catarina/Universidade Federal do Ceará/

$\mathrm{CNPq}$

As relações entre Literatura Comparada e Estudos da Tradução são antigas e, em muitos casos, conflituosas. Em determinados momentos, os Estudos da Tradução eram vistos como um apêndice da literatura comparada; em outros, os Estudos da Tradução ganham força e se colocam no centro da relação. Essas interconexões são descritas por diferentes estudiosos, dentre eles, Susan Bassnett e Emily Apter.

\footnotetext{
* Possui doutorado em Literatura pela Universidade Federal de Santa Catarina. Pós-doutorado pela Università degli Studi di Padova (2010). É professora do Departamento de Línguas e Literaturas Estrangeiras e Coordenadora da PósGraduação em Estudos da Tradução na Universidade Federal de Santa Catarina. Florianópolis, Santa Catarina, Brasil. E-mail andreia.guerini@gmail.com

** Estudou Filologia Românica na Katholieke Universiteit Leuven (Bélgica). Tem Doutorado sobre as traduções de Borges para o inglês pela University of Birmingham, Reino Unido e Pós-Doutorado pela Universidade Federal de Minas Gerais. É professor do Departamento de Língua e Literatura Estrangeiras da Universidade Federal de Santa Catarina. Foi presidente da Abrapt (Associação Brasileira de Pesquisadores em Tradução, na gestão 2010-2013). Atualmente está em colaboração técnica no Departamento de Letras Estrangeiras da Universidade Federal do Ceará. Fortaleza, Ceará, Brasil. E-mail: walter.costa@gmail.com
} 
Como disciplinas acadêmicas separadas, a Literatura Comparada tem uma tradição mais antiga, pois se estabelece no século XIX, enquanto a disciplina de Estudos da Tradução é reconhecida apenas a partir da segunda metade do século XX. Como disciplinas independentes, o campo de exploração de cada uma é imenso, mas o mesmo podemos afirmar de seu entrecruzamento. Foi, então, com o objetivo de estimular o debate, que organizamos este número especial de Cadernos de Tradução, a fim de oferecer ao leitor possíveis caminhos dessa rica relação.

Lucia Boldrini abre o número com o artigo “'L'esprit humain, qui semble voyager d'un pays à l'autre': Considerazioni sulle relazioni storiche tra traduzione e letteratura comparata", que discorre sobre as relações entre literatura comparada e tradução a partir da análise de questões concernentes à construção da linguagem na produção literária e de uma perspectiva histórica, para questionar como isso afeta a conceituação de disciplinas como os Estudos da Tradução e a Literatura Comparada.

Em "Estudos da tradução e literatura comparada: conflito e complementaridade", Walter Carlos Costa analisa a complexa relação dos Estudos da Tradução com a Literatura Comparada, que tem sido de conflito e complementaridade ocorridas de forma desigual nas duas disciplinas.

A partir de uma pesquisa comparatista de tipo descritivista, José Lambert, em "Produção, tradição e importação: uma chave para a descrição da literatura e da literatura em tradução", trata das relações culturais/literárias, tendo como foco a tríade produção-tradição-importação, levando em consideração que a tradução representa uma área-chave em qualquer sistema cultural e, quando se tenta interpretar a posição de certas traduções em um determinado sistema cultural, não há como fugir da tríade produção-tradição-importação, sendo que, na dinâmica entre esses três componenteschave, a posição dominante de um dos componentes pode explicar o porquê da redução dos demais.

Germana Henriques Pereira de Sousa, em "Tradução e sistema literário: contribuições de Antonio Candido para os Estudos 
da Tradução", reflete sobre a relação entre literatura, tradução e formação do sistema literário brasileiro, no sentido da formação de sua tradição, ou seja, estudar a importância da literatura traduzida para a formação do cânone nacional e de como os tradutores participaram ativamente desse processo.

Marie-Hélène C. Torres, em "Mme de Stäel: literatura e tradução", apresenta uma reflexão teórica a respeito do conceito de literatura comparada, principalmente ligada à alteridade e à dimensão estrangeira, e mostra como e por que De la littérature considérée dans ses rapports avec les institutions sociales, de Mme de Staël, é considerada um verdadeiro trabalho "comparatista".

No campo mais prático da Literatura Comparada e Estudos da Tradução, Giorgio de Marchis, em “A tradução dos clássicos e o pó das bibliotecas", analisa uma tradução pouco conhecida de $O$ Primo Basílio publicada na Itália, em 1966, numa coleção popular. Ao oferecer uma contribuição para a reconstrução da fortuna crítica italiana de Eça de Queirós, o autor procura identificar os mecanismos de manipulação literária que, numa tradução, podem deslocar uma obra do centro do cânone para as margens paraliterárias.

Orlando Grossegesse, em "Questões de identidade(s) cruzadas: História do Cerco de Lisboa e Geschichte der Belagerung von Lissabon", mostra como a narração da procura problemática da origem histórica está cruzada com a procura da origem do texto. Ao analisar a densa rede intertextual, na qual se emaranha a revisão criativa de Raimundo Silva, fica patente que a questão central desta metaficção historiográfica é menos a revisão do que a tradução, como o autor evidencia em seu artigo.

Marcelo Paiva, em "Um diálogo no meio do caminho: Czesław Miłosz, leitor e tradutor de Carlos Drummond de Andrade", mostra a estratégia usada por Czesław Miłosz em sua antologia comentada da poesia mundial Wypisy z ksiag użytecznych [Excertos de livros úteis, 1994] para incluir uma única poesia de um único brasileiro: "No meio do caminho", de Carlos Drummond de Andrade.

Dayana Crystina Barbosa de Almeida e Izabela Guimarães Guerra Leal, em "Death By Water: Confluências Entre Mário Faustino E T. 
S. Eliot”, apresenta o diálogo de Mário Faustino com diferentes autores, e de suas traduções. Assim, a partir da comparação entres os poemas "Nam Sibyllam" e "Death by water", este artigo busca mostrar como Faustino deu origem a um novo poema a partir da obra de Eliot.

Denise Bottmann, em "O quinteto da renascença americana no Brasil", apresenta um levantamento que abrange uma ampla bibliografia das obras dos cinco autores que formaram a chamada "Renascença americana", com o objetivo de fornecer uma base de dados para pesquisas na área de Estudos da Tradução e Literatura Comparada.

Para finalizar, esperamos que este número estimule e fortaleça o diálogo entre a Literatura Comparada e os Estudos da Tradução.

Recebido em: 05/01/2015 Aceito em: 05/01/ 2015 